\title{
Explanatory digital video disc with patients undergoing diagnostic cardiac catheterization
}

\author{
Sabrina Koehler Torrano ${ }^{1}$ \\ Verene Beatriz Veiga ${ }^{1}$ \\ Sílvia Goldmeier² \\ Karina Azzolin ${ }^{3}$
}

The aim of this study was to evaluate knowledge of patients before outpatient diagnostic cardiac catheterization after viewing an explanatory Digital Video Disc, in a cardiology reference hospital. This cross-sectional study was carried out with patients undergoing their first cardiac catheterization and was performed from May to June 2009 in the hemodynamic sector. An instrument was used with questions (12) regarding the patients' understanding of the procedure. The intervention was a five-minute video prepared by the researchers. The sample was composed of 94 patients, divided into an intervention group (45) and a control group (49), with a mean age of $55 \pm 9$ years and predominantly male. The patients of

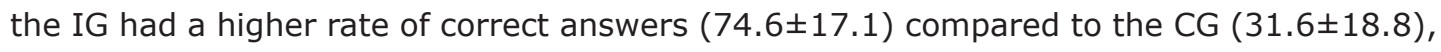
$P=.000$. The results demonstrated the efficacy of the presentation of a guidance video for patients undergoing a hemodynamic procedure.

Descriptors: Nursing; Orientation; Hemodynamics.

\footnotetext{
${ }^{1}$ RN, Graduate Student, Instituto de Cardiologia, Fundação Universitária de Cardiologia, Porto Alegre, RS, Brazil. E-mail: pesquisa@cardiologia.org.br.

${ }^{2}$ RN, Ph.D. in Health Sciences, Professor, Instituto de Cardiologia, Fundação Universitária de Cardiologia, Porto Alegre, RS, Brazil. E-mail: silvia.gold@cardiologia.org.br.

${ }^{3}$ RN, Doctoral Student, Universidade Federal do Rio Grande do Sul, Porto Alegre, RS, Brazil. Professor, Instituto de Cardiologia, Fundação Universitária de Cardiologia, Porto Alegre, RS, Brazil. E-mail: karina.azzolin@ig.com.br.
}

Corresponding Author:

Karina Azzolin

Fundação Universitária de Cardiologia

Rua Princesa Isabel, 370

Bairro: Santana

CEP: 90620-000, Porto Alegre, RS, Brasil

E-mail: karina.azzolin@ig.com.br 


\section{Digital video disc explicativo em pacientes submetidos ao cateterismo cardíaco diagnóstico}

O objetivo deste estudo foi avaliar o conhecimento dos pacientes pré-cateterismo cardíaco com diagnóstico ambulatorial, após digital video disc explicativo, em um hospital de referência em cardiologia. Usou-se o estudo transversal como metodologia, com pacientes submetidos ao primeiro cateterismo cardíaco, realizado de maio a junho de 2009, no setor de hemodinâmica. Foi utilizado instrumento com questões (12) referentes ao entendimento dos pacientes sobre o procedimento. A intervenção foi um vídeo com duração de cinco minutos, elaborado pelos pesquisadores. A amostra foi constituída por 94 pacientes, divididos em grupo intervenção-GI (45) e grupo controleGC (49), com idade média de $55 \pm 9$ anos e predominância do sexo masculino. Pacientes do GI apresentaram maior índice de acertos $(74,6 \pm 17,1)$, quando comparados ao GC $(31,6 \pm 18,8), p=0,000$. Pode-se concluir, por meio dos resultados, que houve eficácia da apresentação de um vídeo de orientações para pacientes submetidos ao procedimento hemodinâmico.

Descritores: Enfermagem; Orientação; Hemodinâmica.

\section{Disco digital explicativo para pacientes sometidos al cateterismo cardiaco diagnóstico}

El objetivo de este estudio fue evaluar el conocimiento de los pacientes sometidos a cateterismo cardiaco tipo diagnóstico en ambulatorio después de ser presentado un DVD explicativo, en un hospital de referencia en cardiología. Se trata de un estudio transversal, con pacientes sometidos al primer cateterismo cardiaco, realizado de mayo a junio de 2009, en el sector de hemodinámica. Fue utilizado un instrumento con 12 preguntas referentes a la atención de los pacientes sobre el procedimiento. La intervención fue un vídeo con duración de cinco minutos elaborado por los investigadores. La muestra constituida de 94 pacientes, fue dividida en grupo intervención (45) y grupo control (49); la edad promedio fue de $55 \pm 9$ años con predominancia del sexo masculino. Los pacientes del GI presentaron un mayor índice de aciertos $(74,6 \pm 17,1)$, cuando comparados al GC $(31,6 \pm 18,8), P=0,000$. Los resultados demostraron la eficacia de la presentación de un vídeo de orientaciones para pacientes sometidos al procedimiento hemodinámico.

Descriptores: Enfermería; Orientacíon; Hemodinámica.

\section{Introduction}

Coronary angiography (CTA) remains the gold standard for diagnosis of coronary obstructions, allowing for appropriate therapeutic planning and providing important prognostic information ${ }^{(1)}$. Although relatively safe, the percutaneous procedures present a multiplicity of adverse events, ranging from minor complications without long-term clinical repercussions to long-term severe conditions with high morbidity and mortality ${ }^{(1)}$. The patients have many expectations, feelings and concerns when they are involved in waiting for an event, especially when this situation deals with something unknown. In situations of hospitalization, medical treatment and diagnostic examinations, the waiting period can become distressful and can lead to stress and anxiety ${ }^{(2)}$. The nursing guidance, in a systematic way, qualifies and contributes to the actions at any level of healthcare and thus increases the knowledge of the patient regarding their disease and the procedures necessary for their treatment, thereby collaborating with the work of the multidisciplinary team ${ }^{(3)}$. One of the complicating factors of this process is the time required for its execution, often impossible due to the number of patients to be cared for and guided. 
Studies that used the Digital Video Disc (DVD) in order to inform patients about cardiac catheterization have presented positive results, especially because they provide patients with greater familiarity with the environment and the technical aspects of the procedure ${ }^{(4-5)}$. Other studies, by adopting the same strategy in different clinical situations, confirmed that the use of a visual resource to support the guidance increases satisfaction and comprehension regarding the procedure to be performed(6-7). Our institution performs approximately 550 cardiac catheterizations per month, 193 angioplasties and 26 primary angioplasties, but there is no systematic pre-procedure methodology to guide the patients, which can result in doubt and anxiety in patients as well as in their family members. Guidance through an audiovisual presentation, clarifying doubts regarding the CTA procedure technique, with language appropriate for the public, was an alternative found in order to decrease anxiety among patients undergoing hemodynamic examination.

In this study, the aim was to evaluate the knowledge of pre-diagnostic outpatient cardiac catheterization patients after viewing an explanatory Digital Video Disc, compared with a group without prior orientation.

\section{Methods}

This cross-sectional study used a Digital Video Disc as a means of guidance to patients undergoing their first cardiac catheterization.

\section{Study Population}

The study included adult patients over 18 years of age, of both sexes, who underwent elective outpatient diagnostic cardiac catheterization in the hemodynamic service of the Cardiology Institute, University Cardiology Foundation of RS during the period May to June 2009. The exclusion criteria were: patients who had previously undergone cardiac catheterization, patients with neurological deficits or those visually impaired.

The study protocol was approved by the Research Ethics Committee of the Institution studied (UP 4255/08). A copy was sent to the Nursing Scientific Committee and all research subjects read and signed the Terms of Free Prior Informed Consent (TFPIC).

\section{Study protocol}

On admission to the hemodynamic service, the patients were directed to the secretary of this sector in order to fill out the attendance form. After registration, the patients were sent to the waiting room of the sector. The nursing technicians asked the patients and their respective family members, to remain in this area. The researchers invited the patients that were going to undergo their first catheterization, to participate in the study. After acceptance, the patients were divided into two groups.

\section{Intervention and control groups}

The first group of patients, the intervention group (IG), first watched the film and then responded to a questionnaire. The second group, the control group (CG), first answered the questionnaire and then watched the film. The questionnaire contained questions relating to the diagnostic cardiac catheterization, thus distributed; 04 concerning the characteristics of the patients, 12 related to the procedure and 01 question that described their feelings about the examination.

A score $\geq 8$ correct answers to the 12 questions was considered as an adequate parameter to measure the knowledge that the patients should possess before being undergoing the CTA. Other authors consider $\geq 70 \%$ correct answers to the questions in the test, which equates to that of our study ${ }^{(8)}$. The questionnaire was completed in the presence of the authors.

Initially, 96 patients referred for elective diagnostic cardiac catheterization were evaluated. Of these, 94 were entered into the database. Two were excluded because they did not complete the questionnaire correctly. In the first week of data collection, patients included in the IG were those registered on Mondays, Wednesdays and Fridays and the CG those on Tuesdays and Thursdays. In the second week the days were interchanged, i.e. the Monday, Wednesday and Friday patients were included in the CG and the Tuesday and Thursday patients included in the IG, which continued until the required sample size was reached. The intervention group (IG) consisted of 45 patients and the control group (CG) of 49 patients.

\section{Intervention}

The video contained information on the operation of the hemodynamic service, with illustrative photos of the service, the team and the type of procedure to be performed, it explained the benefits of the examination, the type of anesthesia, the use of iodinated contrast, the need for fasting and the suspension of medication, the sites indicated for the performance of the examination, the importance of patient cooperation during the examination, and the length of time for the examination and recuperation. The film had an average duration of five minutes. 


\section{Statistical Analysis}

Data were analyzed using the Statistical Package for the Social Sciences software (SPSS V.14.0.). The continuous variables were described as mean \pm standard deviation and categorical variables expressed in absolute numbers and percentages. The groups were compared using the Student's t-test and chi-square test. To investigate the correlations between the groups from the number of correct answers a Box Plot chart was created showing the 25, 50 and 75 percentiles of the groups considering a score of $\geq 8$ correctly answered questions. The value $\mathrm{P}<.05$ was considered significant. According to another study, which evaluated the effect of guidance by means of a video with patients who underwent hemodynamic cardiac procedures, a difference of $39 \%$ to $77 \%$ was found in the knowledge of the patients from the baseline period to the post-

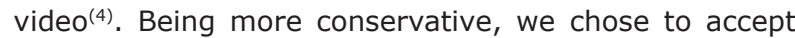
a 35\% difference in knowledge before and after the guidance with a (alpha) of 0.05 and B (beta) of 0.10 with an estimated 46 patients in each group.

\section{Results}

Of the total patients, $58.5 \%$ were male, with mean age of $55 \pm 9$ years. Among the comorbidities, arterial hypertension was the most prevalent (Table 1 ).

Table 1 - Characteristics of the sample $(n=94)$. Porto Alegre, 2009

\begin{tabular}{|c|c|c|c|c|}
\hline Characteristics & $\begin{array}{l}\text { I Group } \\
n=45\end{array}$ & $\begin{array}{c}\text { C Group } \\
n=49\end{array}$ & $\begin{array}{l}\text { Total } \\
n=94\end{array}$ & $\begin{array}{c}P+ \\
n=94\end{array}$ \\
\hline Age (years)* & $55 \pm 9$ & $58 \pm 11$ & $56.6 \pm 10$ & 0.205 \\
\hline Gender (male) & $26(57.8)$ & $29(59.2)$ & $55(58.5)$ & 1.000 \\
\hline Years of study* & $7.2 \pm 3.4$ & $6.9 \pm 3.9$ & $7.0 \pm 3.7$ & 0.652 \\
\hline \multicolumn{5}{|l|}{ Previous diseases } \\
\hline $\mathrm{SAH}$ & $11(24.4)$ & $13(26.5)$ & $24(25.5)$ & 1.000 \\
\hline DM & $6(13.3)$ & $3(6.1)$ & $9(9.6)$ & 0.403 \\
\hline IC & $4(8.8)$ & $3(6.4)$ & $7(7.5)$ & 0.94 \\
\hline Others & $24(53.3)$ & $30(61.2)$ & $54(57.4)$ & 0.573 \\
\hline \multicolumn{5}{|l|}{ Reason for examination } \\
\hline Angina & 15(33.3) & $21(42.9)$ & $36(38.3)$ & 0.461 \\
\hline Medical request & 15(33.3) & $11(22.4)$ & $26(27.7)$ & 0.343 \\
\hline AMI & $6(13.3)$ & $6(12.2)$ & $12(12.8)$ & 1.000 \\
\hline Others & $9(20.0)$ & $11(22.4)$ & $20(21.3)$ & 0.97 \\
\hline
\end{tabular}

* Data presented as mean and standard deviation + for variables age and years of study the Student's t-test was used, for the other variables the chi-square test $\neq$ Systemic Arterial Hypertension § Diabetes Mellitus ๆ Ischemic Cardiomyopathy.

The determinant reason for performing the examination in most cases was angina (38.3\%). Regarding the comparison between the groups, in the IG the number of correct answers was $74.6 \pm 17.1$ and in the CG $31.6 \pm 18.8$ with statistical significance $(P=.000)$. Figure 1 shows the distribution of correct answers according to the percentiles.

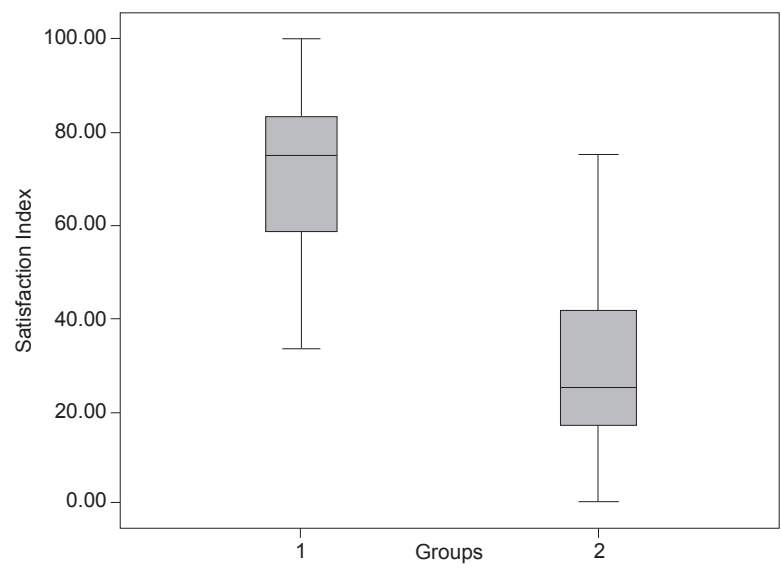

Figure 1 - Median of correct answers between the groups. Porto Alegre, 2009 
The association between age, years of study and number of correct questions was examined between the groups. It was noticed that the variable years of study was correlated to the greatest number of correct answers in the control group $(\mathrm{P}=.005)$ and showed no difference in the IG $(P=.0668)$; between the groups the correlation was weak $(r=0.397)$. The variable age showed no statistically significant difference between the groups. The number of correct answers for each question is shown in Table 2.

Table 2 - Questions related to the hemodynamic procedure. Porto Alegre, 2009

\begin{tabular}{|c|c|c|c|}
\hline Questions & $\begin{array}{c}\text { IG } \\
n(\%)\end{array}$ & $\begin{array}{c}\text { CG } \\
n(\%)\end{array}$ & $\begin{array}{l}\text { Total } \\
\mathrm{n}(\%)\end{array}$ \\
\hline Question 1-Name of the procedure & $40(88.9)$ & $43(87.8)$ & $83(88.3)$ \\
\hline Question 2-Benefits of the procedure & $18(40.4)$ & $8(16.3)$ & $26(27.7)$ \\
\hline Question 3-Type of anesthesia & $35(77.8)$ & $18(36.7)$ & $53(56.4)$ \\
\hline Question 4-Use of iodinated contrast & $27(60.0)$ & $5(10.2)$ & $32(34.0)$ \\
\hline Question 5-Need for fasting & $45(100.0)$ & 41(83.7) & $86(91.5)$ \\
\hline Question 6-Need for stitches & $41(91.1)$ & $5(10.2)$ & $46(48.9)$ \\
\hline Question 7-Part of the body where the examination is performed & $37(82.2)$ & $16(32.7)$ & $53(56.3)$ \\
\hline Question 8-Length of examination & $29(64.4)$ & $6(12.2)$ & $35(37.2)$ \\
\hline Question 9-Suspend medication & $34(75.6)$ & 13(26.5) & $47(50.0)$ \\
\hline Question 10-Length of rest & $40(88.9)$ & $16(32.7)$ & $56(59.6)$ \\
\hline Question 11-Importance of fluids post-examination & $29(64.4)$ & $3(6.12)$ & $32(34.0)$ \\
\hline Question 12-Need to be hospitalized & 28(62.2) & $12(24.5)$ & $40(42.6)$ \\
\hline Question 13-Feelings & \multicolumn{2}{|c|}{ positive $65 \%$} & negative $31 \%$ \\
\hline
\end{tabular}

Among the questions evaluated, No. 1: Name of the procedure and No. 5: The need for fasting, were the best scored, obtaining $88.3 \%$ and $91.5 \%$ of correct answers respectively. Questions No. 2: What are the benefits of the procedure, with $27.7 \%$ of correct answers; and No. 4 : Use of iodinated contrast and No. 11: Importance of the fluids after the examination, both with 34\%, were the questions with fewer correct answers. In relation to question No. 9: Need to suspend any medication, the percentage of correct answers was 50\%, however, only $13.8 \%$ of the patients knew which drugs should be suspended. Of the 94 patients who participated in the study, 61 (65.0\%) had positive feelings, demonstrating tranquility, and 31 (33.0\%) negative feelings, including nervousness and anxiety, regarding cardiac catheterization.

\section{Discussion}

In the quotidian practice of the hospital there is an increasingly significant demand on the hemodynamic laboratories for the performance of cardiac catheterizations for inpatients and outpatients. It is possible to observe on a daily basis, the many different emotional manifestations, triggered by the impact of coronary disease when the uncertainty of what will happen and not knowing the procedure generate concern for the realization of this operation ${ }^{(9)}$. The findings of this study demonstrate the insufficiency of understanding of the patients regarding their disease, the examination, the treatment or therapeutic procedures, without even unanimity on the correct name of the examination. Of the total responses only $27 \%$ of the patients were able to report the benefits of the procedure. These data are similar to an Italian study in which 49 of the 100 patients interviewed, after reading an information leaflet about the procedure, had difficulties of comprehension(4).

A study carried out in 2006, also at the Cardiology Institute of RS, compared the information index between patients of first catheterization and patients with repeat catheterizations, showing results of insufficient knowledge, similar to the present study, regarding the name of the procedure, use of iodinated contrast, length of rest, and the importance of fluid intake, the authors identified the need for more effective nursing guidance $^{(10)}$. Regarding the applicability of the DVD in the guidance of the procedure, better understanding was observed among the patients who watched the video prior to filling in the questionnaire, demonstrated by the greater number of correct answers in the intervention group compared with the control group.

A study with 93 patients undergoing coronary angiography tested the efficacy of an informative video and showed a reduction in the level of anxiety and greater satisfaction according to the information received(5). Another study, with the aim of testing the hypothesis that informed consent presented by video improved the 
comprehension and satisfaction of patients undergoing knee arthroscopy, compared with the traditional verbal informed consent, showed that patients in the video group showed significantly greater comprehension $(78.5 \%)$ than the patients of the verbal group $(65.4 \%)(P=.00001)^{(6)}$. A randomized clinical trial, with 48 orthopedic surgical patients divided into two groups, aimed to evaluate the efficacy of using a videotape to provide patients with information about the risks, benefits, alternatives and treatment of an orthopedic procedure before they signed the surgical terms of consent. The results showed that the video group outperformed the verbal consent group by $40.1 \%$ regarding the initial questionnaire $(P=.0002)$ and $27.2 \%$ in a follow-up questionnaire $(P=.0139)$. Furthermore, the benefit was higher for patients with low levels of education(7).

Although not an aim of this study, the satisfaction of the unit team with the video presentation was noticed, since the patients, after watching it, comprehended factors related to the examination and the dynamics of the service, giving relevant information, for example, regarding the use of medications and allergies and becoming even more tolerant of the waiting period, with these facts being considered an improvement to the service. In the present study, the level of anxiety was not measured, however, the patients were asked about their feelings regarding the procedure and the rate of positive responses exceeded the negative ones. Another possible limitation of the study was not measuring the previous knowledge or the learning needs of these patients, as well as the short time between the DVD guidance and the completion of the questionnaire, however, the aim was only to inform the patient about the hemodynamic procedure.

\section{Conclusions}

The results demonstrated the efficacy of the guidance video presentation for patients who were to undergo the diagnostic cardiac catheterization examination in our service. The video was well received and improved the knowledge of the patients regarding the examination to be performed and the hemodynamic laboratory. The application of this methodology to provide guidance presents a low cost, easy handling and provides group guidance with the visualization of the procedure to be performed. This study enabled the development of a guidance methodology applicable to the reality of the service, which is considered a useful tool due to the high daily demand of patients which complicates the process of individual guidance. It should be noted that new forms of guidance are being tested and validated in order to expand the strategies used by the professionals to improve comprehension of the patients about their illness and the procedures necessary for the instituted therapy.

\section{References}

1. Timerman A, César LAM, Manual de Cardiologia: SOCESP, São Paulo: Atheneu; 2000. 422 p.

2. Grazziano ES, Bianch ERF. Nível de ansiedade de clientes submetidos a cineangiocoronariografia e de seus acompanhantes. Rev. Latino-Am. Enfermagem. 2004;12(2):168-74.

3. Lima LR, Pereira SVM, Chianca TCM. Diagnóstico de enfermagem em pacientes pós cateterismo cardíaco contribuição de Orem. Rev Bras Enferm. 2006;59(3):285-90.

4. Steffenino G, Viada E, Marengo B, Canale R. Nursing and the Medical Staff of the Cardiac Catheterization Unit Effectiveness of vídeo-based patient information before percutaneous cardiac interventions. J Cardiovasc Med. 2007;8(5):348-53.

5. Ruffinengo C, Versino E, Renga G. Effectiveness of informative video on reducing anxiety levels in patient undergoing elective coronarography: An RCT. Eur J Cardiovasc Nurs. 2009;8:57-61.

6. Rossi M, McClellan R, Chou L, Davis K. Informed consent for ankle fracture surgery: patient comprehension of verbal and videotaped information. Foot Ankle Int. 2004; 25:756-62.

7. Rossi MJ, Guttman D, Maclennan MJ, Lubowitz JH. Video informed consent improves knee arthroscopy patient comprehension. Arthroscopy. 2005;21:739-43.

8. Davis $\mathrm{MJ}$, Billett $\mathrm{HH}$, Cohen $\mathrm{HW}$, Arnsten $\mathrm{JH}$ Impact of adherence, knowledge and Qualiy of Life on Anticoagulation Control. Annals Pharmacother. 2005;39(4):632-6.

9. Freitas $M C$, Oliveira $M$, Assistência de enfermagem a idosos que realizam cateterismo cardíaco: uma proposta a partir do modelo de adaptação de Calista Roy. Rev Bras Enferm. 2006;59(5):642-6.

10. Cavalcanti TC, Sarmento-Leite R, Gottschall CAM, Quadros AC, Goldmeir S, Souza EN, et al. Cateterismo Cardíaco Esquerdo: Lacunas nas Informações Transmitidas aos Pacientes. Rev Bras Cardiol Invas. 2008;16(2):206-10. 